\title{
Whitney Ray: CRVENA PTICA / S engleskog prevela Lorea Ajanić
}

Netko je u dvorištu, pomisli Anne. Njišu se grane cedra. Ptice se razbježe prhnuvši s hranilica. Bježe kardinali, plave šojke i domaći vrapci i kroz veliki prozor dnevne sobe bacaju svoje sjene. Tamni obrisi njihovih krila kratko se zadržavaju na baršunastom prekrivaču na Anninim nogama.

Ona pritišće dugme s jedne strane svog bolničkog kreveta, a gornji dio naprave počinje zujati i dizati se sve dok se Anne ne uspravi. Krevet joj je kupio sin u trgovini medicinskom opremom i smjestio ga ispred prozora u dnevnoj sobi, tako da može promatrati svoje ptice na hranilicama. Pritisak dugmeta izaziva joj bol duboko u kostima ruke. Tablete koje svaki dan uzima ne pomažu. Zbog njih Anne se osjeća omamljeno i odvojeno od vlastitog tijela, ali lijek sprečava da bol postane nepodnošljiva. Kako napreduje njezin artritis, tako se i bol širi i postaje sve jača. Čini se da sada dolazi iz same moždine, kao da se ona žuta spužvasta tvar iznutra suši i pretvara u prašinu poput starog spužvastog jastuka.

Anne pogledom prati mladića koji se najednom pojavi i probija kroz nasade cedra i kupine koje okružuju kuću. Šilterica maskirnih boja, štrkljaste noge u trapericama, radne čizme. Nosi pušku zataknutu pod ruku. Zapinje za grančicu kupine, spotiče se i udara glavom u jednu od hranilica. Po ramenima mu padaju sjemenke. Psuje. Klinac, zapravo, pomisli Anne. U ranim dvadesetim, rekla bi. Čelo mu je izbrazdano ožiljcima od akni. Dugačak pramen kose, nešto poput repa štakora, raste mu na zatiljku. Opako izgleda. Podsjeća Anne na njezina sina iz njegovih najluđih godina, na njegove prijatelje odmetnike s kojima je ponekad bježao od kuće. Divlje i agresivne. Pogledava telefon na stolu pokraj kreveta, razmišlja o tome da porazgovara sa šerifom ili da nazove sina u banku u Mason. Stid ju je što se boji mladića kojemu je prije nekoliko godina mogla ponuditi komad pite, ali sada je onemoćala zbog artritisa. Umjerena oduzetost, kaže njezin liječnik. Potpuna će stići naknadno. 
Mladić je ne može vidjeti, podsjeća samu sebe. Blještava proljetna svjetlost pretvara prozore u ogledala. On zuri u kuću i gleda prema ulaznim vratima. Vjerojatno pokušava dokučiti živi li itko u njoj. Otkad je Annin suprug umro, a nju obuzela i pritisnula bol, ta kućica od opeke postala je krajnje zapuštena. Čini se kao da će je proždrijeti okolnih pedeset jutara zemlje. Mladić nestaje iza ugla i Anne ga gubi iz vida. Naginje se i uzima bežični telefon, dok se bol iskričavo širi iz njezina zapešća.

Kucanje na vratima, brzo i snažno. Zadržava dah i sluša. Ponovno kucanje, ovaj put duže i glasnije. Anne se drži za prečku kreveta i lagano ustaje dok gumenu antenu bežičnog telefona drži u zubima. Ulazna vrata udaljena su pet metara. Uzima očev stari štap da se lakše kreće. Ručka mu je glatka i hladna. Dok hoda, koljena joj škripe i gore kao šibice. Kad je stigla do vrata, on opet pokuca. Anne stane na trenutak da dođe do zraka, baca pogled na odjeću. Na njoj su vrećaste hlače s uzicom u struku, ljubičaste kućne papuče i gornji dio trenirke s mrljom od kave s prednje strane. Frizura joj je očajna, treba na šišanje. Nekad je bila vitka, atletske građe, ponosila se time. Čak i dok joj je sin odrastao, uvijek bi sa strane ostavljala novac za fine suknje i bluze. Bila bi lijepa i dobro dotjerana i sada, u šezdeset trećoj godini života, samo da je artritis nije izjedao. Obrazi su joj upali, bokovi bez oblika i spušteni. Više se rijetko kad usudi otići u grad, oslanja se na sina da joj donosi lijekove, gotova smrznuta jela i časopise. Makadamska cesta donosi joj previše boli i neugodno joj je da je ljudi vide tako sasušenu i nakljukanu lijekovima. Mrzi što će je sada vidjeti ovaj nepoznati mladić pa samo odškrine vrata i staje iza njih tako da joj on ne vidi ni odjeću ni štap.

„Izvolite, što trebate?“ upita. Nebo je vedro, modroplavo, a vjetar donosi miris mošusa s procvjetalih stabala bradfordskih krušaka.

„Treba mi telefon.“

Osjetila je miris viskija. Kad je bila mlada, uzbuđivao ju je miris alkohola na Nateovu dahu. Nakon vjenčanja on je postao primjer pravog alkoholičara, svaku večer u štaglju pio je pivo. Zvalo se Pig's Eye. Toliko se brinula o njemu i tako ga je jako voljela, ponekad se morala zapitati nije li i ona poprimila njegove simptome. Zapitati se nije li joj jetra slaba, puna ožiljaka, a jednjak izgrižen. „Pokvario mi se kamion“, kaže mladić. 
Prednji zubi su mu sivkasti. Sramota za nekoga tako mladog. Pita se tko mu je majka i živi li u blizini. Pruža mu telefon kroz vrata. On uzima slušalicu, ali ne bira broj.

„Je li vam muž kod kuće, gospođo?“

Zatečena je. Mora da nije odavde, gotovo svi u gradu čuli su za Nateovu smrt prošle godine.

„Jest, unutra je.“ Ali glas joj drhti. On zuri ravno u nju. Ima svjetloplave oči.

„Moram razgovarati s njim.“

„Zovnut ću ga.“ Pokuša zalupiti vrata, ali on ih zgrabi, gurne širom i Anne se ukazuje pred njim pogrbljena nad štapom.

„Moram ući na minutu“, kaže. Lagano prolazi kraj nje, ulazi u dnevnu sobu i gurne telefon u stražnji džep traperica, jedini telefon u toj prokletoj kući. Luđak, pomisli Anne, pijan, možda na igli, na metadonima. Adrenalin joj izoštrava osjetila i probija se kroz maglu lijekova. Vraća se do kreveta, užasnuta i bespomoćna. Spušta se na madrac, a ruke joj se silovito tresu.

Mladić je u kuhinji, izvaljuje ladice i ormariće. Kroz otvoreni prolaz koji odvaja kuhinju i dnevnu sobu Anne vidi pušku na kuhinjskom stolu, cijev joj se sjaji pod fluorescentnim svjetlom. Zatim gleda veliki kamen s rijeke koji stoji kraj kamina i zamišlja kako ga baca mladiću u glavu. Sjeća se članka koji joj je sin izrezao iz novina prije nekoliko mjeseci, radilo se o jednoj ženi koja je živjela u planinama Novog Meksika i koju je pojeo medvjed kad joj je provalio u sobu. Sin joj je naglasio koliko je opasno živjeti tako samoj, a Anne se samo smijala. Dušo, ovdje već dvjesto godina nije bilo medvjeda. Ali medvjed bi prvo razbacivao kao ovaj mladić, šapama bi prekopao stvari u potrazi za slaninom i tek onda rastrgao ženu.

„Što si lovio?“ Anne dobacuje mladiću. Prava je profesionalka kad treba čavrljati, usavršila je vještinu na nogometnim utakmicama u srednjoj školi. Čini se da je sada razgovor njezina jedina obrana.

„Tuke“, kaže mladić.

Proljetna sezona tuka. Otkad je zatoplilo, cijela jata dolaze i kljucaju sjemenke suncokreta koje ispadaju iz Anninih hranilica. Ona se budi rano, u zoru, samo da ih gleda. Tijela su im okrugla i puna, nekako nezgrapna, za razliku od živahnih kardinala i ptica selica koje skakuću oko hranilica. 
Misli na Natea i kako je svake jeseni išao u lov s njihovim sinom. Uvijek se smijao kad bi se vratili, lice mu je bilo rumeno od hladnoće i nosio bi svežanj pataka uz nogu.

Mladić je našao Nateovu bocu tekile u ormariću iznad štednjaka. Uzima jedan dobar gutljaj i tresne bocom o stol pokraj puške. Nekako sliči na Natea iz mladih dana. Žilav, mišićav, osoran.

„Kako se zoveš?“ upita ga Anne.

„Tanner. A vi, gospođo?“ Ruga joj se, pomisli, ali barem priča. Bilo bi je puno više strah da samo šuti.

Govori mu svoje ime. Tanner joj ne odgovara na pitanje o njegovoj obitelji.

„Muž vam je mrtav, ha?“ kaže Tanner. Anne oblijeva hladan znoj. Možda je primijetio da nema blatnjavih čizama kraj vrata ili prašinu koja je pala po časopisima Poljoprivreda danas.

Mladić ulazi u dnevnu sobu. Pogledom prelazi preko uokvirenih fotografija na zidu, na njima su Nateova farma i kuća slikane iz zraka, iz aviona zaprašivača usjeva sedamdesetih godina. Kuća na njima izgleda kao mali crveni pravokutnik, a polja kao minijaturni kvadrati. Nate je volio te slike, ali Anne se zbog njih osjeća usamljeno, beznačajno. Tanner gleda stalak pokraj njezina kreveta, na kojem su razbacane stare maramice, časopisi i bočice s tabletama.

„Kuća mi je u neredu“, govori mu Anne. „Izluđuje me taj čupavi tepih.“ Zna da brblja bezveze. Tanner uzima bočice sa stolića pa in trese da vidi koliko tableta ima unutra. Anne to podsjeti na zvečku.

„Za što su vam ove?“ pita on.

„Protiv boli, upale. Beskorisne ako nemaš artritis.“

„I vi ste jedna od onih mama iz programa za sprečavanje ovisnosti, je I'?“ Smije joj se i objema rukama grabi bočice s tabletama pa in baca na kuhinjski stol s ostatkom ulova.

Alkohol, lijekovi, novac, misli Anne izbezumljeno. Novac je sljedeće što će tražiti.

„Nemam gotovine u kući“, kaže mu kada on ponovno uđe u dnevnu sobu. Nate je svaku večer gledao vijesti, a Anne je mrzila slušati o pucnjavama i pljačkama. Slučajevi nasilja i zločini činili su joj se tako dalekima i izmišljenima, kao urbane legende. 
Mladić ne odgovara, samo stoji kraj nje i pregledava sobu. Anne gleda kroz prozor. Ptice su se vratile na svoje hranilice. Tri kardinala, dva blistavo crvena mužjaka i siva ženka s narančastim kljunom. Mladić izgleda nesigurno, pomisli Anne. Čini se da ga je napustio pljačkaški zanos.

Anne pokazuje kardinale i govori Tanneru da su joj to najdraže ptice. „Moj suprug ih je zvao crvenim pticama, ne kardinalima. Govorio je da sve crvene ptice u zalazak sunca lete nazad prema Georgiji i prave crvene pruge po nebu. "Anne pred njim izbacuje isječke iz svog života. Želi da je upozna. Sigurno je puno teže opljačkati ili upucati nekoga koga znaš.

Zapravo, čini se da Tanner gleda kardinale. Dva mužjaka na tlu kao da su se porječkala, cvrkuću i napadaju jedan drugog. Kako glupo, pomisli Anne. Iz ove perspektive ne boji ga se. Isti je kao nekad Nate. Jadan, nakon navale alkohola i razmetanja hrabrošću. Namrgođen, kao njezin sin s petnaest godina. Tanner iz džepa traperica vadi pljosku, otpija gutljaj i gleda kako se kardinali svađaju.

„Moj je suprug pio“, govori mu Anne. „Da ti barem mogu reći da ćeš i ti umrijeti od toga, ali on je umro od srčanog udara."

Tanner pruža pljosku Anni i ona je uzima. Njezin oštri metalni otvor na Anninim usnama i osjećaj žarenja jeftinog viskija. Tako ugodno. Šokirana je što pije s razbojnikom. Dugo, predugo se osjećala sputanom, zarobljenom Nateovom smrću i boli koja joj je navalila u zglobove. Koja je to bila muka ponašati se pristojno, glumiti pomirenost sa sudbinom, pretvarati se da je mirna.

Bila je živa vatra u srednjoj školi. Tako ju je otac zvao, živa vatra, i kleo se da će se jednog dana pojaviti trudna i da će je zbog toga morati nekamo poslati. Motala se s dečkima koji su prebrzo vozili, pušila jednu za drugom. Anne je uvijek mislila da doživljava stvari puno jače od ostalih djevojaka, da su joj osjetila naglašenija - kao dugmad za namještanje boje na starim televizorima. Kad je upoznala Natea, bez problema se rano udala, ne zato da bi imala kuću i titulu, nego da vodi ljubav s njim u pravom krevetu, a ne na skučenom zadnjem sjedištu Chevroleta. Bolest je ugušila i umrtvila njezina osjetila. Ipak, sada osjeća da je opet tu u potpunosti, barem tako misli. Potpuno svjesna, prvi put nakon mjeseci i mjeseci.

„Imaš li djevojku?“ upita Tannera. Uzima zadnji gutljaj iz pljoske i vraća je njemu.

„Napucala me.“ Odlazi do Nateova naslonjača i naglo se spušta u njega kao da ima sto kila. 
Anne mu govori da joj je žao i da će brzo naći drugu. Mlad je. Ona se sjeća svog prvog dečka prije Natea, onoga koji ju je ostavio zbog navijačice školske momčadi. Tjednima je imala osjećaj da joj nedostaje zraka, kao da joj je trbuh postao osjetljiv i sav u modricama. Isto se osjećala i kad je Nate počeo ozbiljno piti i kad je umro. Kao da je dobila koljenom u abdomen.

„Dušo, znam kako ti je. Zbog ljubavi se možeš osjećati bolje no ikad ili gore no ikad u životu.“ Kao i dobar seks ili kada vidiš kako ti suprug pada u nesvijest i piša po sebi u dvorištu. Sve se snažno osjećalo, i boje i mirisi.

Govori Tanneru da joj je gledanje ptica pomoglo kad se razboljela i kad joj je suprug umro. I da, kada ih dovoljno dugo gleda, zaboravi na svoje tijelo i ima osjećaj da je dio njih. Da se obrušava na zemlju, da jede poput njih, dok topao zrak prolazi kroz perje.

„Bože, kako je to glupo“, kaže Anne. „Zvučim kao ove lude new age knjige.“

Tanner zagunđa i ispusti nekakav zvuk kao da potvrđuje što je rekla. Čini se da ga je njezin glas uljuljao, gotovo uspavao. Tada se naglo trgne i skoči iz naslonjača.

„Gdje je torbica? Kutija s nakitom?" Sad već skoro viče. Od adrenalina Anne se suši grlo, koče ruke. Opasan je, poremećen. Zavaravala se osjećajem suosjećanja prema njemu. Ne može se sjetiti gdje joj je torbica, možda na komodi u spavaćoj sobi? Njezin vjenčani prsten u kutiji je s nakitom. Prsti su joj previše natečeni za nošenje prstenja.

Iz kuhinje se čuju Tannerovi koraci, stavlja ruku na kundak puške.

„Gospođo, ne zajebavajte se sa mnom!“

Anne mu govori da ponekad ne može razmišljati kako treba, ali da bi torbica i nakit trebali biti u spavaćoj sobi, dolje niz hodnik. Kutija za nakit je od hrastovine, njezin sin izradio ju je za nju u osmom razredu na satu tehničkog.

Čuje Tannera u svojoj spavaćoj sobi, baca stvari, izvlači ladice komode. Nešto tresne na pod. Vjerojatno zlatni okvir s fotografijom Anne i Natea s vjenčanja. Neka sve ide k vragu, misli ona, Nate je nikad ni od čega nije morao štititi. Nikad nije bilo provalnika ni pljačke, nikad u četrdeset dvije godine braka. Jedino što je ikada napravio bilo je to što je pucao na rakune u kantama za smeće. Ona traži od Natea neku nadnaravnu pomoć, govori mu da će joj taj mladić uzeti vjenčani 
prsten. Od bijesa osjeća knedlu u grlu. Čuje samu sebe kako naglas govori „molim te“. Pada joj mrak na oči i zna da će se onesvijestiti, što joj se prošle godine već nekoliko puta znalo dogoditi. Naglo joj se zavrti, ugleda patku, netko ju je upucao u letu, strmoglavljuje se prema tlu.

On je podiže. Osjeća njegovu mišićavu ruku ispod svojih koljena i kako joj stavlja svoj dlan pod glavu. Sigurno je smješta na njezin bolnički krevet. Osjeća kako joj gura deku pod noge. Nate, pomisli. Sjeća se kako se zabrinuo kad se razboljela. Kuhao joj je litre i litre vrućeg, zaslađenog čaja, nespretno pokušavao pripremiti obroke. Otvara oči i ugleda mršavog mladića kako se naginje nad njom, blijed je i zabrinut. Miriše na znoj. Nedostaje joj miris muškog znoja. Njezin sin miriše na papir i na one osvježivače zraka s mirisom borovine iz banke.

„Nisam vas ozlijedio“, kaže Tanner. „Znate to, je li tako? Samo sam ušao...“

$\mathrm{Ne}$, misli Anne, nisi me ozlijedio. Natea više nema. Moje tijelo samo sebe napada. Dušo, ti mi najmanje škodiš.

Pogledom prelazi dnevnom sobom i vidi da su joj torbica od umjetne kože i kutija s nakitom bačene na pod. Njezina ogrlica od žućkastih bisera leži na smeđem tepihu. Tanner odlazi od nje, čučne i počinje skupljati komade nakita. Vidi ga kako joj uzima zlatni prsten.

„Molim te, nemoj to uzeti.“

„Gospođo, žao mi je, jako mi je žao, ali vi ne znate u kakvim sam ja problemima.“

Anne se sjeća kako je svog sina, dok je bio tinejdžer, učila da se cijeli svijet ne vrti oko njega. To je isto željela reći i Nateu. Nikad nije shvaćala njegovu ogorčenost. Ogorčen zbog čega, zato što u životu nije napravio više, zato što je samo uzgajao pšenicu i podigao zdravu obitelj? Pita se odakle dolazi ta mladićeva ljutnja? Iz siromaštva, od loših roditelja, djevojke koja ga je ostavila? Na vratu i ramenima osjeća kako joj popušta bijes, kao da netko otkopčava tijesnu haljinu. Sve se raspliće. I kuća i njezino tijelo raspadaju se, a Natea više nema. Dovraga, koliko bi je moglo povrijediti to da izgubi taj prsten? lonako ga više ne može nositi.

„U kuhinji ispod sudopera ima vrećica od Wal-Marta ako ti treba“, kaže mu Anne. Osjeća se iscrpljeno. Gleda Tannera kako stavlja u vrećicu tablete, bocu, torbicu i nakit kao dijete kad sprema svoju užinu. Nakon toga vraća se u dnevnu sobu natovaren dvjema vrećicama i puškom.

Groteskna maškara. Glupo. Sjeća se Natea nekoliko dana prije smrti: izvaljen u naslonjaču, 
okrugla trbušina, odvaljena čeljust. Kako je samo ljutito izgledao kada je bio pijan, kao da su ga varali cijeli život.

„Nećete nikoga zvati, je l' tako, ako vam ja sada vratim telefon?" upita Tanner.

„Neću.“

„Ne“, kaže on. „Gospođo, žao mi je, jako.“ I otrči prema vratima, a telefon se ocrtava na izbočenom stražnjem džepu njegovih hlača.

Ona zuri kroz prozor i gleda ga kako se opet s mukom probija kroz grmlje, a uplašene ptice brzo bježe s hranilica. Nema ga više, kao da ga nikad nije ni bilo. Ona jednim dijelom želi da je još tu. Možda je mogla razgovarati s njim da se više potrudila. Kad je pokušala natjerati Natea da razgovaraju, bio je već prestar i pretvrdoglav. Pita se kada će je sin posjetiti i vidjeti kako je. Želi van. U kući je zagušljivo i vruće. Bol joj se širi tijelom dok ustaje iz kreveta. Bez štapa šepa kroz dnevnu sobu, vuče noge poput sakatog konja i umalo se spotakne o kutiju za nakit.

Otvara vrata i osjeća nalet vjetra. Stoji na stepenicama trijema, jednom rukom drži se za rub kuće i gleda sive oblake kako zaklanjaju sunce. Jorgovan je prepun cvjetova. Guli se plava boja na Nateovu starom traktoru. Boje su blistave. Bože, pomisli Anne, tako dugo nisam bila vani. Prelazi jezikom preko desni i još osjeća okus Tannerova lošeg viskija. Misli na njegove ruke pod svojim koljenima, na njegov znoj koji miriše na kvasac. Sjeća se kako bi prislonila svoje lice na Nateov vrat kada bi se vratio s njive, samo da osjeti slanoću znoja. Hladan vjetar mrsi joj kosu, a jedan kardinal kao da joj cvrkuće „dragadragadraga." Anne diže pogled i vidi jednog zagasitocrvenog mužjaka kako je gleda sa stabla cedra, a njegova krila kao da plamte među tamnozelenim granama.

\section{(c) (i) (3)}

Creative Commons Attribution-NonCommercial-NoDerivatives 4.0 International License 